\title{
Profissão docente: uma rede de histórias
}

\author{
Isabel Lelis \\ Departamento de Educação, Pontifícia Universidade Católica do Rio de Janeiro
}

A idéia de investir na pesquisa sobre trajetórias de vida de professoras das séries iniciais do ensino fundamental ${ }^{1}$ nasceu da insatisfação com um discurso sobre a desqualificação dos saberes e práticas do magistério, visto como incompetente tecnicamente e descompromissado politicamente na tarefa de ensinar setores das camadas populares. Gestado a partir dos anos de 1980, especialmente no interior das burocracias educacionais, este discurso tem servido à definição de políticas de controle pelo Estado sobre o trabalho do professor através de mecanismos de racionalização e privatização ${ }^{2}$ de ensino.

${ }^{1}$ Este trabalho está baseado em minha tese de doutorado $A$ polissemia do magistério: entre mitos e histórias, defendida em 1996, na PUC-Rio. A escolha das professoras entrevistadas ocorreu em função dos seguintes critérios: estarem trabalhando no primeiro segmento do ensino fundamental; estarem na sala de aula há pelo menos 15 anos; terem inserção em espaços variados: escola privada leiga, escola privada confessional e escola pública municipal, localizadas em bairros da zona sul, norte e oeste da cidade do Rio de Janeiro.

${ }^{2}$ Para Nóvoa (1998b), a racionalização e privatização do ensino são dois momentos de um mesmo processo de controle ex-
Em que pese a necessidade de encontrarmos formas de regulação da profissão docente, que respeitem a experiência do professor e levem em consideração processos dinâmicos e interativos de formação continuada, vivenciados em espaços locais pelo coletivo deste grupo profissional, o que se assiste hoje em vários países do mundo é uma lógica que, em nome da qualidade do ensino, da descentralização e da inovação, tem privilegiado estratégias no campo do currículo e da formação de professores com sérios desdobramentos sobre a autonomia das instituições escolares. (Nóvoa,1998b, p. 170).

Neste sentido, trabalhar com narrativas biográficas significou poder problematizar essa lógica que se manifesta na representação de uma categoria profis-

terno da profissão docente. Fazem parte de uma agenda política que tende a definir os professores a partir de critérios de racionalidade técnica, "colocando entre parênteses os saberes, as subjetividades, as experiências, em outras palavras as histórias pes-soais e coletivas dos professores" (p. 169). Em um modelo dirigido pelo mercado, a pretensa autonomia concedida aos professores nada mais é do que uma auto-regulação, individual e coletiva, fundada em um discurso racional, objetivo e científico (p. 168). 
sional marcada por classificações apriorísticas em termos dos saberes e habilidades que deve ser portadora, do grau de profissionalismo que deve alcançar. Representou, na verdade, uma possibilidade de refletir sobre abordagens fundadas em sistemas que demarcam e moldam como deve ser o mundo (Popkewitz, 1992), que a meu ver são prisioneiras tanto de uma tendência a um "abstracionismo", ao ignorar a dinâmica das práticas escolares (Azanha, 1992, p. 46), como de um "substancialismo" que cancela os movimentos no tempo e no espaço dos agentes sociais.

Na opção pela abordagem biográfica, tinha uma convicção de que nenhuma (história de) vida é simplesmente uma trajetória isolada. "Ao contrário, sempre se acha inscrita numa matriz, mais ou menos vasta e complexa de relações sociais que em larga medida a informam, da qual retira parte considerável da sua própria lógica e que, necessariamente, acaba também por refletir" (Almeida, 1995, p. 133).

Por este caminho, foi possível identificar mapas de orientação para a vida social e profissional a partir de condições sociais de existência reveladoras de valores, atitudes e comportamentos de agentes e grupos sociais (Velho, 1987).

Se é verdade que a literatura internacional que nos chegou na última década sobre a profissão e profissionalização docente foi extremamente estimulante do ponto de vista dos perigos que cercam o controle político do trabalho docente, com a consequiente separação entre as atividades de concepção e execução, das ideologias que sustentam o princípio da racionalidade técnica presente na definição de profissão docente, também é verdade que é preciso investir na compreensão dos vários sentidos atribuídos ao trabalho docente para além de certas formulações que insistem em discutir se o magistério é profissão, ocupação semiprofissionalizada ou em via de profissionalização (Nóvoa, 1998b; Perrenoud, 1996).

Este debate parece estar preso a concepções que avançam pouco sobre a tensão entre a pluralidade de significados conferidos à profissão pelos professores e um projeto mais orgânico que possa dar conta dos desafios da escola de massa e da valorização de seus agentes, os profissionais de ensino, especialmente em contextos marcados pela seletividade social e escolar.

Em recente livro sobre o ofício do professor, Arroyo (2000) introduz uma imagem de que a cultura do magistério é constituída de muitos fios e de que privilegiar uma única dimensão é não dar conta da complexidade do trabalho docente. Com base nesta imagem, pretendo, neste texto, refletir sobre a identidade social do magistério, forjada em processos de socialização familiar, escolar e profissional. Utilizo-me para tanto de histórias de vida de professoras moradoras na cidade do Rio de Janeiro que atuam em escolas públicas e privadas do ensino fundamental. A intenção é a de revelar fragmentos dos processos invisíveis de constituição de habitus $^{3}$ profissionais e, com isto, relativizar imagens de incompetência técnica e passividade, presentes em relatórios e documentos oficiais. Trata-se de afirmar que a história social do magistério é uma arena feita de um conjunto de histórias que se interpenetram: história da construção do campo intelectual da educação e da profissão, história das lutas e estratégias dos professores em relação ao Estado, história da construção da escola e do conhecimento que nela circula. Mas também história feita do modo como professores "agem, pensam, sentem, convivem... dentro e fora do trabalho, na totalidade de seus espaços e tempos, de suas relações sociais" (Arroyo, 2000, p. 199).

${ }^{3}$ Para Ortiz (1983), é Bourdieu quem recupera a dimensão de aprendizado passado na idéia escolástica de habitus, como modus operandi, disposição estável para se operar numa determinada direção (p. 14). Sua reinterpretação da noção de habitus ocorre no embate objetivismo/fenomenologia, passando a ser definida como: "sistema de disposições duráveis, estruturas estruturadas predispostas a funcionarem como estruturas estruturantes, isto é, como princípio que gera e estrutura as práticas e representações que podem ser objetivamente 'regulamentadas' e 'reguladas' sem que por isso sejam o produto de obediência a regras, objetivamente adaptadas a um fim, sem que se tenha necessidade da projeção consciente deste fim ou do domínio das operações para atingi-lo, mas sendo, ao mesmo tempo, coletivamente orquestradas sem serem o produto da ação organizadora de um maestro" (Bourdieu, 1972, p. 61). 


\section{Entre o público e o privado, como fica a imagem do magistério?}

Mais do que qualquer outra categoria profissional, a situação atual do magistério das séries iniciais no Brasil tem sido fartamente alardeada pela mídia e pela produção acadêmica. Seja do ponto de vista da origem social, seja do ponto de vista do grau de instrução obtido, ou ainda sob a ótica das condições de trabalho, o reconhecimento da diversidade social e cultural entre professores amplia as dificuldades do debate em torno da sua imagem social e pública. De um lado, a desvalorização é assinalada, tendo como matriz a escola de massa e a democratização de ensino, com a conseqüente perda de prestígio ligado à posse de um saber, não acessível à maioria da população. De outro lado, a imagem permanece elevada, pelo menos simbolicamente, pois sobre os professores são colocadas a expectativa e a responsabilidade social por esperanças de um futuro melhor (Nóvoa, 1998b). Entre as duas tendências, o que está em causa é o próprio projeto de uma escola de massa que não consegue dar conta do aumento dos alunos e sua heterogeneidade sociocultural, do impacto de novas formas de tratar o conhecimento e o ensino (Lelis, 1997b).

Em que pese a complexidade que envolve o lugar social ocupado pelo magistério, o que se verifica nas narrativas das professoras é um movimento ascendente na trajetória social e instrucional, se considerarmos as suas famílias de origem. Em boa parte provenientes de setores com baixa escolaridade, desenvolveram, ao longo de seus itinerários, estratégias de conquista de títulos escolares à custa de renúncia e austeridade em termos de estilo de vida, de uma ascese no sentido de que fala Bourdieu (Nogueira, 1991).

É o caso de Isolda, uma professora negra, moradora em bairro proletarizado do Rio de Janeiro, cuja história de vida é marcada pela tenacidade em superar obstáculos de toda ordem nos planos social e econômico. Iniciando a sua vida como professora particular aos doze anos, para ajudar a família, vai galgando os degraus da escolarização até obter o diploma de licenciatura em Letras em uma universidade federal de prestí- gio. Após concluir o curso universitário, Isolda submete-se a concursos públicos para escolas secundárias da rede federal de ensino, tendo sido aprovada em todos os exames. Entretanto, por não possuir experiência comprobatória em instituições de ensino médio, não consegue ser admitida, dadas as exigências do próprio sistema de seleção. Consumidora de livros desde a infância e adolescência, o diploma de ensino superior, conquistado duramente por iniciativa pessoal e fora da jornada de trabalho, provocou pequeno deslocamento de posição no campo profissional, uma vez que passa a atuar também em séries mais avançadas do ensino fundamental. Perguntada sobre a força da experiência universitária, relativiza a função do saber acadêmico que não lhe permitiu ascensão na carreira docente do ponto de vista do exercício em grau de ensino mais elevado. Depois de muitos anos na docência em escolas públicas municipais, estimulando as crianças e jovens a serem leitores e escritores através do recurso à pesquisa em jornais e à encenação de peças teatrais, justifica os movimentos efetuados na trajetória como expressão da tensão entre a instabilidade profissional e a manutenção de posição conquistada no itinerário, típica de camadas médias de origem desfavorecida.

Através do caso de Isolda e de tantas outras professoras, o que fica evidenciada é a necessidade de pensar o processo de profissionalização da profissão docente para além da lógica do espaço acadêmico e das políticas do Estado inscritas em um campo de poder, como adverte Nóvoa (1998b). E, mais, sugere o desafio de acolher um grau de universalismo que o termo profissão comporta (Tardif, 2000) mas também a possibilidade de incluir formas peculiares de entrar na profissão e viver o trabalho docente em contextos sociais que ainda não equacionaram o problema de desigualdade social e da seletividade escolar. Indo mais longe, estimula a refletir sobre o sentido da experiência e do conhecimento universitário para a prática profissional (Tardif, 2000), especialmente para segmentos das classes trabalhadoras que investem no "estudo" como projeto construído em função de experiências socioculturais de um código, de vivências e interações interpretadas (Velho, 1987). 
Com isto, não estou desqualificando o papel dos conhecimentos - disciplinares, curriculares, da ação pedagógica - trabalhados pelas instituições responsáveis pela formação do magistério, mas chamando a atenção para o fato de que os saberes dos professores trazem a marca das suas experiências pessoais, sendo, portanto, temporais, heterogêneos e situados (Tardif, 2000).

Certamente, o investimento em pesquisa sobre vidas de professores pode significar uma chave de análise fecunda para entender seu desenvolvimento profissional. Mas a identidade social das professoras comporta também imagens de esvaziamento de recursos culturais que o magistério vem sofrendo, especialmente nas últimas décadas, geradas por condições de trabalho adversas, seja por acumular a função em um ou mais estabelecimentos de ensino, seja por trabalhar em educação mas não em docência, seja ainda em ocupação não relacionada ao ensino (Gatti et al., 1998). Com baixo status socioeconômico, a dupla ou tripla jornada de trabalho tem repercussões sobre o cotidiano das professoras, como a diminuição de freqüência a museus, concertos musicais, cinemas, viagens. Nos depoimentos dados, salvo exceções, o sentimento manifestado é o da perda gradativa do gosto pela leitura, das restrições vividas em termos do acesso a bens culturais com desdobramentos sobre o estilo de vida e o trabalho destas profissionais (Lelis, 1997a).

A este quadro, devem ser acrescentadas dificuldades de atualização em serviço, enfrentadas pelos docentes da rede pública, o que acaba por se expressar na baixa freqüência a cursos, seminários e oficinas. Em estudo desenvolvido com professores das oito séries da rede pública de três estados - Maranhão, Minas Gerais e São Paulo -, Gatti et al. (1998) chamam a atenção para a prática da leitura, registrada como pouco significativa nos 304 questionários analisados, amostra estratificada por localização, séries, disciplinas e nível socioeconômico da clientela:

Embora 69\% dos professores declarem que lêem alguma revista de educação, a atividade de leitura especializada por parte dos professores não parece ser muito intensa: $14 \%$ deles declaram não ter lido nada nos últimos anos e
$52 \%$ dizem que leram apenas alguns textos ou artigos. Só $18 \%$ dizem ter lido livros com regularidade. Boa parte dos que afirmam ter lido algum texto nos últimos três anos não foi capaz de citar nenhum autor ou título e percentual significativo citou apenas um. (Gatti et al., 1998, p. 256)

Ana, professora de língua portuguesa, ensina em dois turnos em uma escola municipal, localizada em bairro da zona sul do Rio de Janeiro. Concluiu os cursos de letras, de música e de belas-artes em universidade federal, tendo obtido títulos acadêmicos de reconhecido valor no mercado científico. Esta professora vem de família de artistas e parece ter desenvolvido uma relação mais desenvolta com a cultura dita "cultivada". Seu pai foi professor de matemática, teve livros de poesia publicados. A atmosfera da casa era marcada pela valorização e pelo gosto do teatro e da música. O estilo de vida de Ana sofreu mudanças significativas nos últimos anos, expressando-se na restrição à compra de livros e frequiência a teatros, concertos de música, viagens. Em sua narrativa, a perda do poder aquisitivo, gerada pela deterioração dos salários pagos ao magistério municipal, acabou por comprometer sua existência, impedindo o acesso a planos de seguridade social.

O que sua história revela e que se poderia estender para parte do magistério é um esforço de incorporação de capital cultural, ${ }^{4}$ na qual o "ter" passou a "ser", uma propriedade feita corpo, tornada prática in-

${ }^{4}$ Em seu texto "Os três estados do capital cultural”, Bourdieu (1979) define: "O capital cultural pode existir sob três formas: no estado incorporado, ou seja, sob a forma de disposições duráveis do organismo; no estado objetivado, sob a forma de bens culturais - quadros, livros, dicionários, instrumentos, máquinas, que constituem indícios ou a realização de teorias ou de críticas dessas teorias, de problemáticas etc.; e, enfim, no estado institucionaliza$d o$, forma de objetivação que é preciso colocar à parte porque, como se observa em relação ao certificado escolar, ela confere ao capital cultural - de que é supostamente, a garantia - propriedades inteiramente originais" (p. 74). Esta noção ajuda a compreender a transmissão doméstica do capital cultural enquanto investimento educativo poderoso realizado pelas famílias com impacto no desempenho escolar das crianças de diferentes classes sociais. 
tegrante, um habitus (Bourdieu, 1972) certamente com desdobramentos sobre a prática profissional. Contraditoriamente, o fato de ter conquistado títulos acadêmicos, capital cultural institucionalizado, não representou garantia de obtenção de vantagens nos planos social e econômico, sinalizando para certo grau de imprevisibilidade que envolve trajetórias de indivíduos e grupos sociais.

Considerando que as transformações de estilo de vida acabaram por atingir a subjetividade e sociabilidade destes agentes sociais se compararmos com décadas passadas, a imagem pública dos professoras revela-se problemática, pois, ao lado da representação social de pouco competentes ou pouco qualificadas para o exercício da profissão, o imaginário social está fundado ainda na retórica da missão, do sacerdócio e da vocação, matrizes de fundo religioso que atravessam fortemente a história deste grupo profissional.

Sem compartilhar do ideário da vocação que sugere chamamento, personalismo, dom, graça divina (Haguette, 1991) e escamoteia a posição ocupada pelos professores no espaço social, e refletindo sobre as condições de vida dos alunos e as necessidades que estes impõem à dinâmica escolar - que incluem violência doméstica, ausência dos pais no processo de escolarização dos filhos, consumo de drogas entre crianças e jovens -, os professores vêm sendo levados a desenvolver estratégias de ensino e de interação que considerem o trato com as novas características da clientela. Nesse sentido, não viraram as costas às condições de existência de seu alunado, como tão insistentemente a literatura dos anos de 1980 enfatizou. $\mathrm{Na}$ perspectiva de que o professor precisou alterar suas práticas diante da fome, da miséria, das jovens mãessolteiras, das famílias desintegradas, Vorraber Costa (1995) chama a atenção para a distância que existe entre, de um lado, o discurso - objetivo e racional sobre profissionalismo, reafirmado em retóricas neoliberais, nos textos oficiais e, de outro lado, as práticas sensíveis e solidárias desenvolvidas por professoras, muito distantes das lógicas definidoras do que deva ser a profissão docente. Como o objeto do trabalho do docente são seres humanos, os saberes que advém desta experiência precisam ser refletidos, legitimados (Tardif, 2000) sob pena de se cancelar uma dimensão estruturante da prática. Esta é, contudo, uma face invisível da profissão que tem permanecido invisível e pertence à esfera privada, não sendo explorada consistentemente nos programas de formação.

Culpabilizados por não responderem às exigências da atividade escolar cotidiana, os docentes situam-se em um fogo cruzado de poderes e contrapoderes em uma história de isolamento no interior da sala de aula, que contribui para impedir uma mudança do seu status sociocultural, apesar dos movimentos empreendidos por associações profissionais, universidades e sindicatos, especialmente a partir do final dos anos 70.

Pensando alternativas para uma nova identidade docente, Nóvoa (1998b) adverte para a necessidade de se superar uma visão de miserabilidade que acabou por envolver os professores e que interfere sobre a ação pedagógica e sobre o ethos do magistério das séries iniciais. Somente uma cultura de colaboração, de parceria entre Estado, universidades, organismos da sociedade civil e escolas, respeitosa em relação às ferramentas didáticas que os professores dispõem no espaço escolar poderá contribuir para a administração dos problemas que sociedades como a nossa ainda apresentam e que lhes chegam através dos comportamentos e práticas dos alunos.

\section{Tempos e espaços de formação}

Mais do que qualquer outra profissão, o magistério das séries iniciais tem sido historicamente associado ao ideário social fundado no dom ou na aptidão que só as mulheres naturalmente possuiriam, sendo a escolha da profissão explicada pela oportunidade que a mulher encontra para pôr em prática habilidades que aprendeu desde o nascimento (Bruschini, 1978), uma estratégia de sobrevivência, um poderoso senso de realidade diante dos constrangimentos impostos à mulher até os dias atuais. Trabalhando sobre trajetórias, o que se verifica é que o gênero é uma categoria importante de compreensão da entrada na profissão, devendo, con- 
tudo, ser articulado à classe social, etnia, geração, pois não somos vistos apenas com o nosso sexo ou o que a cultura fez dele (Lopes, 1991). Diferentes construções sociais do gênero feminino manifestam-se na forma como as professoras entraram, permaneceram e têm atuado na profissão. Fatores como uma certa familiaridade com a profissão, desenvolvida no interior dos grupos de referência, o peso da educação feminina, um campo de possibilidades restrito em termos socioeconômicos, a necessidade imediata de obtenção de emprego seguro em mercado de trabalho aberto, a conciliação entre estudo e trabalho (Lelis, 1996; Gatti et al., 1998) concorreram para a constituição de disposições mais ou menos favoráveis ao magistério, ou seja, em muito atuou, nos relatos das professoras, a força da socialização familiar, expressa em práticas culturais, redes sociais de circulação, constrangimentos econômicos.

Outro elemento, que passa pela entrada no ofício, ajuda a entender a imagem social da docência. Contrariando o debate em torno dos critérios de recrutamento para a carreira de professor, e dos saberes e das habilidades que devem possuir, as histórias de vida de professoras, originárias das camadas desfavorecidas, apontaram para um percurso que se inicia precocemente em escolas adaptadas no espaço doméstico e em aulas particulares, como "explicadoras" para alunos que estavam fracassando na escola pública. Trata-se de uma rede paralela ao sistema oficial de ensino, na qual se desenvolve um trabalho marcado pela domesticidade, porta de entrada para a profissão, percorrida por algumas das entrevistadas no processo informal de se tornarem professoras. No trabalho "a domicílio", as professoras jogam o jogo possível de ser jogado, administram a continuidade/descontinuidade do tempo de trabalho em função de seu próprio cotidiano.

Clara conta que desde criança gostava de brincar "dando aulas" com botões, imaginariamente percebidos como "classe" de alunos. O início de sua prática se dá através de aulas particulares, que de tão bem sucedidas transformam-se em "escolinha" funcionando em sua casa, na zona rural da cidade. Esta atividade se prolonga por muitos anos e torna-se estratégia para o pagamento de curso superior de Letras, feito à noite em instituição de ensino superior próxima a sua residência, de baixo prestígio acadêmico. Obtém também a licenciatura em Pedagogia como forma de ampliar o campo de alternativas profissionais. Alguns anos mais tarde, inicia um curso de pós-graduação em literatura infantil em universidade federal, que não pode ser concluído pela tripla jornada de trabalho. Sua inserção formal no magistério da rede pública se deu por concurso para séries mais elevadas do ensino fundamental. Entretanto, por opção, trabalhou ainda por alguns anos em escola improvisada na paróquia de uma igreja próxima a uma favela. Afirma que sua entrada no magistério ocorreu por caminhos tortuosos, nos quais "voltou para trás", numa alusão à preferência pelo ensino primário das camadas populares em detrimento da escola secundária.

Analisando o ofício do professor, Weber (1997) nos faz ver como é complexa esta problemática e como a domesticidade pode se constituir em sério obstáculo ao processo de profissionalização docente, pois a sua superação implica não apenas na definição de outros padrões de remuneração, mas também na delimitação de competências, na institucionalização de requisitos do ponto de vista da formação inicial e do próprio exercício da atividade. Sua existência remete à problemática da profissão vista como campo, no sentido atribuído a este termo por Bourdieu, ${ }^{5}$ marcado por uma lógica particular e por hierarquias e disputas. Permite a visualização dos professores enquanto sujeitos que ocupam posições distintas e contribuem com as ferramentas teóricas e práticas que possuem e que adqui-

${ }^{5}$ O campo, para Bourdieu (1983), é um espaço social que possui estrutura própria, relativamente autônoma em comparação a outros espaços sociais, isto é, a outros campos sociais. Os campos se definem através de objetivos específicos, o que lhes garante uma lógica particular de funcionamento e de estruturação. É característico do campo possuir suas hierarquias e disputas internas, assim como princípios que lhe são inerentes, cujos conteúdos estruturam as relações que os atores estabelecem entre si e no seu interior. 
ram em seus percursos para a mudança ou permanência na e da instituição escolar.

Pensando a trajetória de Clara, caberia refletir: sua experiência docente certamente é síntese de acertos e equívocos. Mais do que julgar esta trajetória, a exigência está em pensar as relações que esta professora construiu com o saber e com o saber fazer. Dito em outras palavras, qual o peso da socialização escolar e profissional nas práticas que foi construindo? Como o saber acadêmico alterou disposições nascidas na fase inicial da docência, quando ainda experimentava doméstica e intuitivamente recursos didáticos, até porque os paradigmas de formação de professores tendem a tratar "os alunos como espíritos virgens e não levam em consideração suas crenças e representações anteriores a respeito do aluno?" (Tardif, 2000 p. 19).

Quando passamos às instituições propriamente formadoras de professores, o desafio está na heterogeneidade destas instituições do ponto de vista da qualificação acadêmica oferecida. Se é verdade que o processo de passagem da formação para o ensino superior significou, na última década, uma luta do campo dos educadores no sentido de garantir uma fundamentação teórica mais consistente ao futuro professor, uma relação mais direta com a teoria que só a universidade poderia oferecer, há outras dimensões deste fenômeno que precisam ser analisadas sob pena de estarmos passando ao largo dos significados que a formação prévia ocupa nos itinerários de professores. Considerando que nas últimas décadas proliferaram cursos noturnos de ensino superior em escolas privadas sob condições de funcionamento e de ensino muito precárias, e que "seria ingênuo acreditar que a formação inicial pode ser o único motor de profissionalização" até porque "a formação de professores só pode influenciar as suas práticas em determinadas condições e dentro de determinados limites" (Perrenoud, 1993, p. 153), é compreensível o fato de que a maioria das professoras ter se referido a este espaço e tempo como pouco estimulante do ponto de vista intelectual. Falas como "Não é a faculdade que faz o aluno, o aluno é que chega lá com sua bagagem...", "Eu não tinha desejo nenhum de fazer Pedagogia... acabei desistindo depois do primei- ro semestre..." fazem-nos pensar na necessidade de recolocar no centro da discussão a complexidade da profissão docente e como corolário a formação de professores. Para Nóvoa, o desafio está na “análise histórica do currículo dos cursos de formação de professores que tem oscilado entre três pólos: metodológico, com uma atenção privilegiada às técnicas e aos instrumentos de ação; disciplinar, centrado sobre o domínio de um saber; científico (pedagógico) tendo como referência as ciências da educação, enquadradas elas mesmas pelas ciências sociais e humanas,em particular, a Psicologia”. Com este tipo de lógica, reproduzem-se dicotomias (conhecimento fundamental/conhecimento aplicado, ciência/técnica, saber/métodos etc.) que não contribuem para pensar a relação dos professores com o saber" (Nóvoa, 1998b, p. 172)

Quanto às escolas normais, instituições tradicionalmente voltadas para a formação de professores, especialmente em regiões menos desenvolvidas do Brasil, Gatti et al. (1998) chamam a atenção para problemas que se arrastam há décadas, como a desarticulação entre os diferentes tipos de conhecimentos que compõem o currículo, a redução e o esvaziamento das disciplinas de caráter instrumental, a ausência de projetos pedagógicos organicamente construídos pelos docentes. Na qualidade de local por onde circulam contingentes expressivos de jovens, os anos passados em escolas normais bem poderiam ser considerados como "anos descoloridos", tal é a falta de glamour da instituição, agravados pela não-escolha e não-adesão a tornar-se professora (Weber, 1997).

Para aquelas docentes que exaltaram este espaço de formação, as memórias são a excelência de ensino, a consistência do trabalho realizado pelos professores, a boa formação cultural. Em que pesem imagens tão diferentes sobre o papel da formação inicial na construção de um modo de ser professora, duas ordens de questões precisam ser colocadas. A primeira relaciona-se à força da socialização familiar e escolar na configuração de sistemas de pensamento comum a toda uma geração, isto é, as disposições que organizam o pensamento e a prática - duráveis e transferíveis - são tributárias destas duas instituições, família e escola, o 
que não significa que não comportem uma "arte de invenção" (Bourdieu, 1974). Pensando o trânsito entre a experiência escolar e o início do exercício profissional, Nóvoa nos dá uma pista para este processo de passagem:

Este fato acentua um dos traços sociológicos da profissão docente: um professor primário passa de um papel (o de estudante) para seu oposto (o de professor). No processo de sua entrada na profissão, os docentes efetuam uma roletransition em vez de um role-reversal e, no início de sua atividade profissional, utilizam frequientemente referências adquiridas no momento em que eram alunos: num certo sentido, pode-se dizer que o crucial da profissionalização do professor não ocorre no treinamento formal mas em serviço. (Nóvoa, 1991, p. 91)

A segunda questão refere-se às exigências que devem pautar a formação inicial de professores, independente do nível desta formação. Quer esta formação aconteça na universidade, quer se desenvolva em escolas normais ou ainda em institutos superiores de educação, o desafio está em reconhecer que nenhuma destas instâncias poderá isoladamente dar conta de suas necessidades. É importante introduzir a escola, enquanto espaço promotor de aprendizagem e de reflexão teórico-metodológica da prática (Gómez, 1992), como eixo estruturante da formação. Pensar a produção de uma consciência crítica e da ação qualificada para o futuro professor implica não abrir mão da pessoa do professor, da organização escolar e da profissão em um plano coletivo (Nóvoa, 1998a).

\section{A força da escola na socialização profissional dos professores}

Assistimos na última década ao aparecimento de uma literatura voltada para pensar os professores como pesquisadores e como profissionais reflexivos. Esta tendência representa, sem dúvida alguma, a busca por requalificação dos docentes do ponto de vista social e profissional. Metodologicamente, tem-se passado a valorizar abordagens biográficas no horizonte de que o "modo de vida" pessoal acaba por interferir no pro- fissional. Em que pese a heterogeneidade das obras com estes recortes e do perigo que ronda a própria utilização das narrativas autobiográficas, ${ }^{6}$ é importante reter alguns consensos. $\mathrm{O}$ primeiro deles diz respeito à necessidade de afirmar a importância das dimensões teóricas, técnicas e pessoais do trabalho docente, tendo em vista o resgate da autonomia profissional dos professores, ameaçada no contexto da racionalização e privatização do ensino. O segundo relaciona-se à valorização dos saberes de referência da profissão a partir da reflexão dos próprios professores sobre sua prática (Nóvoa, 1998a). Ora, a escola é o lugar privilegiado capaz de redimensionar os saberes de que são portadores os professores, que se manifestam na ação pedagógica, e as concepções sobre os processos de ensinar e aprender que informam uma série de comportamentos e atitudes.

Katia é uma professora que tem dupla inserção: trabalha em escola pública e em escola particular, ambas localizadas em bairro da zona norte da cidade. Esta professora construiu sua identidade profissional de fato na escola privada na qual trabalha há vinte anos. Trata-se de escola de prestígio no conjunto das instituições particulares pelos resultados obtidos por seus alunos nos vestibulares da cidade e do estado do Rio de Janeiro. Katia não conseguiu freqüentar o curso de pedagogia, já que tem dupla jornada de trabalho e é arrimo de família. Mais do que socializada, esta escola foi a grande agência formadora de idéias, valores e práticas na vida desta professora, já que a escola pública em que leciona encontra-se em processo de deterioração, sendo alta a rotatividade dos professores. Em seu depoimento, não há referência a seminá-

${ }^{6}$ Bourdieu (1996) chama a atenção para a ilusão biográfica e utiliza-se da metáfora do nome próprio para questionar supostas permanências atribuídas por filiação, estado civil, profissão, expressão de instituições juridicamente instituidoras de posições em espaços sociais. Para este autor, compreender uma vida como sucessão de acontecimentos é tão absurdo como explicar um trajeto de metrô, sem levar em conta a estrutura da rede, a matriz das relações objetivas entre diversas estações. 
rios, oficinas, cursos nem a programas de entretenimento, compra e leitura de livros. Katia é professora em classes de alfabetização e diz utilizar uma série de recursos para ensinar a ler e escrever as crianças: músicas para lançar fonemas, tipos de material concreto para o ensino da matemática.

Diante deste fragmento de narrativa, duas questões se colocam. O fato de Katia estar imersa em uma instituição privada com determinada atmosfera pedagógica pode tê-la levado a vestir o "hábito de monge" de que fala Bourdieu (1983), não lhe permitindo "estranhar o familiar" (Velho, 1987), tal é a adesão ao projeto pedagógico da instituição da qual foi uma das autoras. Se parece haver espaço nesta escola para a formação continuada de seu corpo docente, já que o ideário da instituição passa pelo investimento na reflexão coletiva, o desafio está em pensar se a adesão incondicional à escola lhe permitirá uma reflexão sobre a ação mais liberta dos constrangimentos impostos pela própria instituição. A segunda questão relaciona-se à hipótese de que a dimensão pedagógica do trabalho se relaciona a outras esferas da vida social, isto é, as práticas que professores realizam não são assépticas no sentido de estarem livres das posições que ocupam no espaço social. Suas disposições profissionais são síntese viva de um conjunto de experiências relativas às marcas da escolarização a que foram submetidos, aos processos de formação prévia, à cultura da organização escolar na qual construíram uma forma de ser professor, pessoal e intransferível.

\section{À guisa de conclusão}

Pensar a construção social do trabalho docente a partir de trajetórias de vida de professoras representou um esforço de superação de perspectivas etnocêntricas que tendem a definir a profissão a partir de um olhar "para dentro", enclausurado no campo científico e político. Este olhar historicamente tem virado as costas à uma trama complexa de práticas, valores e saberes daqueles que fazem a escola quotidianamente.

Para além da passividade e incompetência técnica do magistério, julgada e arbitrada pelas agências governamentais e burocracias do Estado, o que importa é compreender que os professores ocupam posições diferenciadas em termos dos recursos que dispõem e que construíram em suas histórias. Por esta via, não haveria um único profissionalismo mas formas particulares de viver o trabalho, nem sempre visíveis, nem sempre revestidas de características comuns, inclusive do ponto de vista de um patamar em termos da formação inicial desejável. As diferenças devem ser afirmadas, pois encerram condições objetivas de produção dos sujeitos sob as quais construíram formas de perceber e classificar o mundo. O caráter polissêmico do trabalho docente não deve servir, contudo, de pretexto ao imobilismo das instituições responsáveis pela formação de professores - administrações públicas, universidades, sindicatos. Deve constituir o eixo para a definição de políticas públicas voltadas de fato para a valorização social do magistério nos seus vários significados.

Se esta reflexão representou uma das versões da história social da profissão no Brasil nesta virada de século, o futuro está em aberto e vai depender do jogo de poderes e contrapoderes, das tensões e conflitos que cercam a profissão de professores.

ISABEL ALICE LELIS, doutora em educação pela PUC-Rio, é professora no Departamento de Educação dessa mesma Universidade. Além dos textos citados na bibliografia acima, publicou: $A$ formação da professora primária: da denúncia ao anúncio. São Paulo: Cortez, 1993, já em terceira edição; Do ensino de conteúdos aos saberes do professor: mudança de idioma pedagógico? Educação e Sociedade, v. 22, nº 74, abril de 2001, dossiê "Os saberes docentes e sua formação”. E-mail: isabell@edu.puc-rio.br

\section{Referências Bibliográficas}

ACCARDO, Alain, CORCUFF, Philippe, (1986). La sociologie de Bourdieu; textes choisis et commentés. Bordeaux: Editions Le Mascaret.

ALMEIDA, Manuela, (1995). As histórias de vida enquanto procedimento de pesquisa sociológica; reflexões a partir de um processo de pesquisa. Revista Crítica de Ciências Sociais, $\mathrm{n}^{\circ} 44$, p. $125-141$. 
ARROYO, Miguel, (2000). Ofício de mestre; imagens e auto-imagens. Petrópolis: Vozes.

AZANHA, José Pires, (1992). Uma idéia de pesquisa educacional. São Paulo: EDUSP.

BOURDIEU, Pierre, (1972). Esboço de uma teoria da prática. In: ORTIZ, Renato (org.). Pierre Bourdieu. São Paulo: Ed. Ática, 1983, p. $46-81$

(1974). Sistemas de ensino e sistemas de pensamento. In: MICELLI, Sérgio (org.). A economia das trocas simbólicas. São Paulo: Perspectiva, p. 203-229.

(1979). Os três estados do capital cultural. In: NOGUEIRA, Maria Alice, CATANI, Afrânio (orgs.). Pierre Bourdieu: escritos de educação. Petrópolis: Vozes, 1998, p. 71-79.

(1983). O campo científico. In: ORTIZ, Renato (org.). Pierre Bourdieu. São Paulo: Ed. Ática, p. 122-155.

(1996). Razões práticas sobre a teoria da ação. São Paulo: Papirus.

BRUSCHINI, Cristina, (1978). Mulher e trabalho: engenheiras, enfermeiras e professoras. Cadernos de Pesquisa, n 27, p. 3-18.

GATTI, Bernardete, ESPOSITO, Yara, NEUBAUER DA SILVA, Rose, (1998). Características de professores(as) de $1^{\circ}$ grau: perfil e expectativas. In: SABINO, Raquel et al. (org.). Formação de Professores. São Paulo: Editora Unesp, p. 251- 265.

GOODSON, Ivor, (1992). Dar a voz ao professor: as histórias de vida dos professores e o seu desenvolvimento profissional. In: NÓVOA, Antonio. Vidas de professores. Portugal: Porto Editora, p. 63-78.

GÓMEZ, Angel Pérez, (1992). O pensamento prático do professor; a formação do professor como profissional reflexivo. In: NÓVOA, Antonio (org.). Os professores e sua formação. Portugal: Publicações Dom Quixote, p. 93-114.

HAGUETTE, André, (1991). Educação: bico, vocação ou profissão?. Educação e Sociedade, no 38, p. 109-121.

LELIS, Isabel, (1996). A polissemia do magistério; entre mitos e histórias. Doutorado em Educação. PUC-Rio, Rio de Janeiro.

(1997a). Modos de trabalhar de professoras: expressão de estilos de vida?. In: CANDAU, Vera Maria (org.). Magistério, construção cotidiana. Petrópolis-RJ: Vozes, p. 150-160. (1997b). O magistério como campo de contradições. Contemporaneidade e Educação, ano 2, no 2, p. 143-155.

LOPES, Eliane Marta, (1991). A educação da mulher: a feminização do magistério. Teoria e Educação, nº 4, p. 22-41.

NOGUEIRA, Maria Alice, (1991). Trajetórias escolares, estratégias culturais e classes sociais; notas em vista da construção do objeto de pesquisa. Teoria e Educação, nº 3 .

NÓVOA, Antonio, (1991). Para o estudo sócio-histórico da gênese e desenvolvimento da profissão docente. Teoria e Educação, $\mathrm{n}^{\circ}$ 4, p. $109-139$.

(1998a). Relação escola-sociedade: novas respostas para um velho problema. In: SABINO, Raquel et al. Formação de Professores. São Paulo: Editora Unesp, p. 19-40.

(1998b). Histoire e comparaison; essais sur l'éducation. Lisbonne: Educa Éditeur.

ORTIZ, Renato, (1983). Introdução: A procura de uma sociologia da prática. In: ORTIZ, Renato (org.). Pierre Bourdieu. São Paulo: Ed. Ática, p. 7-36.

PERRENOUD, Philippe, (1993). Práticas pedagógicas, profissão docente e formação. Portugal: Publicações Dom Quixote.

(1996). Enseigner: agir dans l'urgence, décider dans l'incertude. Paris: ESF Editeur.

POPKEWITZ, Thomas, (1992). Profissionalização e formação de professores: algumas notas sobre a sua história, ideologia e potencial. In: NÓVOA, Antonio (org.). Os professores e sua formação. Lisboa: Publicações Dom Quixote, p. 35-50.

TARDIF, Maurice, (2000). Saberes profissionais dos professores e conhecimentos universitários: elementos para uma epistemologia da prática profissional dos professores e suas conseqüências em relação à formação para o magistério. Revista Brasileira de Educação, São Paulo, Anped, n 13, p. 5-24.

VELHO, Gilberto, (1987). Individualismo e cultura; notas para uma antropologia da sociedade contemporânea. Rio de Janeiro: Jorge Zahar.

VORRABER COSTA, Marisa, (1995). Trabalho docente e profissionalismo. Porto Alegre: Sulina.

WEBER, Silke (1997). A desvalorização social do professorado. Contemporaneidade e Educação, ano 2, nº 2, p. 156-170. 
work and school education. The discourse of the subjects of the research reveals the conflict between the formation required for cooperative agricultural work and the model of basic education on which rural education is based.

\section{Isabel Lelis}

Profissão docente: uma rede de histórias

Este artigo tem o objetivo de analisar a identidade social do magistério das séries iniciais do ensino fundamental, forjada em processos de socialização familiar, escolar e profissional. Através do recurso às histórias de vida de treze professoras, foi possível perceber que muitos são os significados atribuídos ao trabalho docente. Recorrendo ao aporte da sociologia de Pierre Bourdieu, o trabalho permitiu compreender a constituição de habitus para a docência, as estratégias desenvolvidas pelas professoras para a conquista de títulos escolares, os modos de entrada na profissão, o peso da formação prévia e continuada nas formas como as professoras vivem e representam o trabalho que realizam. Considerando que a representação social do magistério, no contexto de uma escola de massa, foi alterada, o estudo acabou por problematizar imagens de passividade, negligência e incompetência que têm sido atribuídas às professoras pelas burocracias educacionais e agências governamentais.

The teaching profession: a webs of stories

This article proposes to analyse the social identity of teachers in the first series of primary education, forged through processes of professional, school and family socialization. Using the life stories of thirteen women teachers, the article discusses the significance attributed to the teaching profession. Taking Pierre Bourdieu's sociology as reference, the study explores the constitution of the habitus in teachers, the strategies they use to achieve academic qualifications, admission to the profession and the weight of initial and continued training in the way teachers experience and represent their work. This study challenges the images of passivity, negligence and technical incompetence that are attributed to teachers by educational authorities and governamental agencies, by recognizing that, at a time in which a massification of school is occuring, the social representation of teaching has been modified.

\section{Claudio Suasnábar}

Resistência, mudança e adaptação nas universidades argentinas: Problemas conceptuais e tendências emergentes no governo e na gestão acadêmica

$\mathrm{O}$ artigo propõe-se a fazer uma contribuição ao debate teóricometodológico dos referenciais conceptuais mais adequados para o estudo dos problemas do governo e da gestão universitária na Argentina.

Este trabalho também constitui uma primeira posta à prova do instrumental apresentado. São analisadas as tensões que geram as políticas estatais na gestão acadêmica. Considerase que a emergência de uma dupla linha de gestão e condução na institucionalização de novos atores nas universidades argentinas configuram os dois fenômenos que disputam o papel historicamente atribuído aos conselhos acadêmicos. Essas tensões, que hoje percorrem os processos de mudança institucional, expressam o conflito entre as novas formas de gestão e o modelo de co-governo que instaurou a Reforma Universitária de 1918.
Resistance, change and adaptation in argentine universities: concept problems and tendencies emerging from academic government and management

This article aims to contribute to the theoretical and methodological debate on the most suitable conceptual frameworks for studying the problems of government and management in Argentinian universities. The paper also constitutes a first test of the instruments presented therein. Tensions generated by state policies on academic management are also analysed. The article considers that the emergence of a double line of manegement and condut of the institution of new actors in Argentinian universities constitute the two phenomena which dispute the role historically attributed to academic councils. These tensions, which underlie processes of institutional change the, are the expression of conflicts between new forms of management and the model of cogovernment that established the Argentinian University Reform of 1918.

Afrânio Mendes Catani, Denice Bárbara Catani e Gilson R. de M. Pereira

As apropriações da obra de Pierre Bourdieu no campo educacional brasileiro, através de periódicos da área

A partir de pesquisa realizada em 20 periódicos especializados em educação, editados entre 1971 e 2000, são analisadas as formas de apropriação da obra de Pierre Bourdieu no campo educacional brasileiro. O conjunto dos 355 artigos publicados nesses periódicos que fazem referências ao sociólogo constitui o corpus básico para a análise das peculiaridades das interpretações brasileiras do autor. 